\title{
A taxonomically and geographically constrained information base limits non-native reptile and amphibian risk assessment: a systematic review
}

\author{
Nicola J. van Wilgen ${ }^{\text {Corresp., }}{ }^{1,2}{ }^{\text {, Micaela S. Gillespie }}{ }^{2}$ ， David M. Richardson ${ }^{2}$ ， John Measey ${ }^{2}$ \\ ${ }^{1}$ Cape Research Centre, South African National Parks, Steenberg, Western Cape, South Africa \\ 2 Centre for Invasion Biology, Department of Botany \& Zoology, University of Stellenbosch, Matieland, South Africa \\ Corresponding Author: Nicola J. van Wilgen \\ Email address: nvanwilgen@gmail.com
}

For many taxa, including reptiles, new records of non-native introductions globally occur at a near exponential rate. We undertook a systematic review of peer-reviewed publications on non-native herpetofauna, to assess the information base available for assessing risks of future invasions, resulting in 836 relevant papers. The taxonomic and geographic scope of the literature was also compared to a published database of all known invasions globally. We found 1116 species of herpetofauna, 95\% of which were present in fewer than twelve studies. Nearly all literature on the invasion ecology of herpetofauna has appeared since 2000 , with a strong focus on frogs (58\%), particularly cane toads (Rhinella marina) and their impacts in Australia. While fewer papers have been published on turtles and snakes, proportionately more species from both these groups have been studied than for frogs. Within each herpetofaunal group, there are a handful of well-studied species: Rhinella marina, Lithobates catesbeianus, Xenopus laevis, Trachemys scripta, Boiga irregularis and Anolis sagrei. Most research (416 papers; $50 \%$ ) has addressed impacts, with far fewer studies on aspects like trade (2\%). Besides Australia (213 studies), most countries have little location-specific peer-reviewed literature on non-native herpetofauna (on average 1.1 papers per established species). Other exceptions were Guam, the United Kingdom, China, California and France, but even their publication coverage across established species was not even. New methods for assessing and prioritizing invasive species such as the Environmental Impact Classification for Alien Taxa provide useful frameworks for risk assessment, but require robust species-level studies. Global initiatives, similar to the Global Amphibian Assessment, using the species and taxonomic groups identified here, are needed to derive the level of information across broad geographic ranges required to apply these frameworks. Expansive studies on model species can be used to indicate productive research foci for understudied taxa. 
1 A taxonomically and geographically constrained information base

2

4

$7{ }^{1}$ Centre for Invasion Biology, Department of Botany and Zoology, Stellenbosch University, P/Bag x1,

8 Matieland, 7602, South Africa

$9 \quad{ }^{2}$ Cape Research Centre, South African National Parks, PO Box 216, Steenberg, 7947

10

11

12

13

14

15

\section{systematic review}

\section{*nvanwilgen@gmail.com; nicola.vanwilgen@sanparks.org}

12 Short title: Non-native reptiles and amphibians 
16

17

\section{Abstract}

For many taxa, including reptiles, new records of non-native introductions globally occur at a near exponential rate. We undertook a systematic review of peer-reviewed publications on non-native herpetofauna, to assess the information base available for assessing risks of future invasions, resulting in 836 relevant papers. The taxonomic and geographic scope of the literature was also compared to a published database of all known invasions globally. We found 1116 species of herpetofauna, $95 \%$ of which were present in fewer than twelve studies. Nearly all literature on the invasion ecology of herpetofauna has appeared since 2000 , with a strong focus on frogs $(58 \%)$, particularly cane toads (Rhinella marina) and their impacts in Australia. While fewer papers have been published on turtles and snakes, proportionately more species from both these groups have been studied than for frogs. Within each herpetofaunal group, there are a handful of well-studied species: Rhinella marina, Lithobates catesbeianus, Xenopus laevis, Trachemys scripta, Boiga irregularis and Anolis sagrei. Most research (416 papers; 50\%) has addressed impacts, with far fewer studies on aspects like trade (2\%). Besides Australia (213 studies), most countries have little location-specific peer-reviewed literature on non-native herpetofauna (on average 1.1 papers per established species). Other exceptions were Guam, the United Kingdom, China, California and France, but even their publication coverage across established species was not even. New methods for assessing and prioritizing invasive species such as the Environmental Impact Classification for Alien Taxa provide useful frameworks for risk assessment, but require robust species-level studies. Global initiatives, similar to the Global Amphibian Assessment, using the species and taxonomic groups identified here, are needed to derive the level of information across broad geographic ranges required to apply these frameworks. Expansive studies on model species can be used to indicate productive research foci for understudied taxa.

Key-words: Alien species, biological invasions, crocodiles, exotic, frogs, lizards, risk assessment, salamanders, snakes, turtles 
41

42

43

44

45

\section{Introduction}

Alien or non-native species are taxa that have been transported beyond the limits of their natural range, and may become invasive in new areas if they are able to form established, self-sustaining populations in these new locations (Blackburn et al. 2011). For several taxa, new invasions continue to occur at a near exponential rate (Seebens et al. 2017). Evidence of the negative impacts of many invasive species (e.g. Pimentel 2011), including impacts from reptiles and amphibians (Shine 2014; Kraus 2015; Measey et al. 2016) is increasing. This has added urgency to the pursuit of achieving a thorough understanding of factors mediating success at different stages of the introduction-naturalization-continuum (Richardson et al. 2000; Blackburn et al. 2011) to inform policies to reduce the risk of further invasions. Effective and defensible policies are increasingly being introduced, or considered, to attempt to curb invasions at a national level (e.g. Genovesi, Carboneras, Vilà \& Walton 2015), but require robust models to differentiate between innocuous and potentially problematic species (Springborn, Romagosa \& Keller 2011). The challenges posed to the assessment of invasion risk are unique to each taxonomic group (Kumschick \& Richardson 2013). Such challenges include strategically prioritising research on the impacts of understudied species, in areas of the world where invasive species are less studied and different aspects of the invasion process less well covered. Although fairly robust models exist to explain the success of introduced plants (e.g. Pheloung, Williams \& Halloy 1999), formal risk assessment still faces multiple challenges even for this group (Hulme 2013; Speek, Davies, Lotz \& van der Putten 2013).

Invasions of reptiles and amphibians ("herpetofauna"), although not nearly as well documented as plant invasions (Pyšek et al. 2008), have received significant attention in recent years, 
64 especially in Florida (Krysko et al. 2011), with an emphasis on species in the pet trade and

65

66

67

68

'hitchhiker' species (Tingley et al. 2018). While there are currently relatively few invasive reptiles and amphibians, some species do have significant impacts (Kraus 2015; Measey et al. 2016) and records of first introduction for reptiles at least, have been increasing at an exponential rate since the 1950s (Seebens et al. 2017). Numerous studies have investigated the factors that influence the popularity in the pet trade, probability of introduction and release (e.g. Stringham \& Lockwood 2018), and the likelihood of successful establishment of herpetofaunal species in new regions. Several strong and consistent patterns have emerged from these studies. For example, establishment success is enhanced for species introduced and released in high numbers (Garcia-Diaz, Ross, Ayres \& Cassey 2015; Mahoney et al. 2015), into areas with high native species richness (Tingley, Phillips \& Shine 2011; Ferreira et al. 2012; Poessel et al. 2013), for species that are less manageable (more expensive to keep, prone to escape, aggressive or venomous, Fujisaki et al. 2009), that have fast-paced life histories (Allen et al., 2017, van Wilgen \& Richardson 2012), and that come from areas with similar environmental conditions to the area of release (Bomford, Kraus, Barry \& Lawrence 2009; van Wilgen, Roura-Pascual \& Richardson 2009; Tingley, Phillips \& Shine 2011; Rago, While \& Uller 2012). However, models using these predictors, can be relatively data hungry, making it difficult to regulate the import of species and prioritize management of those already present in an area in the absence of primary data. This is increasingly leading to disillusionment among traders who challenge restrictions placed on the importation of certain taxa and could spur illegal imports. Increasing objectivity and a better understanding of uncertainties are necessary to inform communication between legislators, managers, conservationists and pet traders. 
87 Formal pre-border risk assessment, which is increasingly becoming mandatory in many countries

88

89

90

91

92

93

94

95

96

97

98

to regulate the import of species that are not yet present, faces important challenges. Risk is defined by both the probability of an event taking place and the consequences of such an event (Kumschick \& Richardson 2013). Most risk assessments for non-native reptiles and amphibians to date have focused on the potential for a species to establish (event probability). Another approach recently proposed is to assess the impacts of non-native species based on known impacts in other parts of its non-indigenous range (EICAT: Blackburn et al. 2014; Hawkins et al. 2015; SEICAT: Bacher et al. 2018). This approach, and others like it (e.g. Kumschick et al. 2015; Nentwig et al. 2016), attempt to provide an index to denote the likelihood of impact if a species is introduced into a new location, for example through trade. Managers could use these simple indices to inform decision-making. Unlike most risk-assessment protocols, EICAT and SEICAT rely exclusively on a systematic review of peer-reviewed publications of each species in their non-indigenous range. This 'gold standard' of data sources carries with it the need for a comprehensive set of literature on all non-native species, but assessments to date have highlighted problems with the assumption that sufficient published material exists. For example, an assessment of all non-native bird populations found published material detailing ecological impact for only 30\% of 415 species (Evans, Kumschick \& Blackburn 2016). A similar assessment for non-native amphibians found information on ecological impact for only $38 \%$ of 105 species (Kumschick et al. 2017), and socio-economic information for only $7 \%$ of these species (Measey et al. 2016; Bacher et al. 2018). It would be naive to assume that such biases result from an absence of impacts; it is well known that reporting biases exist between different taxa, and between continents/global regions (Dawson et al. 2017). However, until the extent of biases are better understood, it remains difficult to motivate studies on non-native species in poor 
110 or underdeveloped localities, even though such data may be of great value to more developed

111 nations who have legal and logistical infrastructure to prevent importation.

113 We aim to assess the information currently available to inform quantitative risk assessments of

114 herpetofauna and the degree of taxonomic and geographic bias that exists in the literature. To do

115 this, we performed a systematic review of research published to date on non-native reptile and

116 amphibian species to assess the scope of peer-reviewed information currently available. In so

117 doing, we highlight the species, subjects and geographic locations that received the most

118 research, and enable identification of gaps.

\section{Survey Methodology}

121 For this analysis we split reptiles and amphibians into six taxonomically-based 'morphological 122 groups' (hereafter herpetofaunal groups): lizards, snakes, turtles, crocodiles, frogs and

123 salamanders, recognizing that snakes and lizards are not separate monophyletic groups.

124 However, this distinction is reflective of the level at which these groups are often studied (e.g.

125 Rodda, Sawai, Chiszar \& Tanaka 1999) as a result of their distinct morphological characteristics

126 and different selection pressures on these groups in the pet trade that result in divergent invasion

127 patterns as well as other functional differences that are likely to affect their invasion probability.

129 To determine the knowledge base underpinning existing risk assessments for herpetofauna, we reviewed the literature available on the introduction, establishment and/or invasion and impact of 
131 non-native reptiles and amphibians. Searches were conducted on the ISI Web of Science Core

132 Collection (on 3 March 2016) using the following criteria: Topic = alien OR invasive OR non-

133 native OR exotic OR non-indigenous OR feral AND Topic= reptil* OR amphibia* OR turtle*

134 OR tortoise* OR lizard* OR herpetofauna OR crocod* OR anura OR caudata OR testudin* OR

135 ophidia OR sauria OR squamata OR snake* OR frog* OR toad* OR salamand* OR newt*. The

136 ISI subscription used literature dating back to 1970. We recognise that ISI is biased in many

137 respects, including against non-English literature (e.g. Adam 2002). However, we justify the use

138 of this database alone as it is a source likely to be used by those conducting risk assessments, and

139 for whom non-English language content may also be inaccessible. This search yielded 3194

140 papers. Many of these papers were not relevant to the current study as a result of a number of

141 homonyms (e.g. invasive and non-invasive medical techniques) that resulted from including the

142 wide range of search terms (Westgate \& Lindenmayer 2017). As a preliminary measure to

143 reduce the papers from extraneous study fields (Westgate \& Lindenmayer 2017), the results were

144 refined by excluding irrelevant research areas (e.g. paediatrics and ophthalmology, see the full

145 list in supplementary material), leaving us with 2383 papers (Fig. 1). The relevance of these

146 papers was assessed by reading the abstract and, where necessary, the full paper. All studies that

147 pertained to non-native herpetofaunal species were included in the review. These included those

148 that addressed any aspect of the invasion process (e.g. establishment or potential establishment

149 correlates, or bioclimatic models); impacts or potential impacts (including ecological impacts,

150 human socio-economic impacts, spread of disease and envenomation); potential or actual spread

151 dynamics; genetics of introduced populations; detectability; ecology in non-native range (diet,

152 reproduction, interactions with other species); biology in non-native range; and factors relating to

153 import or pathways of invasion, including trade in non-natives and translocation of non-natives; 
154 or first records of populations. Studies focussing on the impacts of non-herpetofaunal non-native

155 species (e.g. mammals or fish) on native reptiles and amphibians were excluded, as were purely

156 veterinary studies, studies on parasites of non-native species where the parasite and not the non-

157 native species was the focus, and any papers that had no clear link to the topics of interest (e.g.

158 despite the filter on the research areas, the search identified a large number of papers from other

159 disciplines, such as invasive versus non-invasive medical techniques). This final list included

160836 papers that were used in the quantitative analysis.

162 For each paper, the identity of all non-native reptiles and/or amphibians included in each study

163 was recorded, as was the country or US state (locality) in/across which the study took place.

164 Species recorded from papers included those that were the direct focus of study (e.g. for which

165 field data were collected or species that were included in an experimental setup) and any species

166 documented in a particular place outside of their native range. We recognize that detailed studies

167 of single species are probably more useful to risk assessors. However, papers that provide

168 general overviews of many species are also valuable (with specified confidence limitations) for

169 risk assessment when specific information about focal species is not available, and also to

170 provide evidence of pathways and introduction records, where introduction represents an

171 important phase of invasion (Blackburn et al. 2011). Each paper was also classed into one or

172 more of the following subject categories: Climate, Ecological Impacts, Pathways, Control,

173 Invasion Correlates, Distribution, Translocation, or Trade. Once all data were captured, the

174 taxonomy of species was cross-checked using Frost (2017) for amphibians and Uetz, Freed and

175 Hošek (2017) for reptiles, and relevant entries in the database were consolidated. The family to

176 which each species belongs, and the total size of these families, and herpetofaunal groups, were 
177 taken from the same sources. Many papers that covered more than one taxon included species

178 that were non-native, but had not necessarily been released into the wild, or did not have

179 established populations. We did not attempt to remove these species from our list, which leads to

180 discrepancies in numbers between our dataset and those of Kraus (2009). We did however

181 compare results for papers that dealt only with one species with those that dealt with multiple

182 species as well as the full set of papers, but found no difference in the focus of these subsets of

183 publications. The full dataset is available as supplementary material (S2). Summary statistics

184 were calculated by paper, subject and species.

186 We assessed taxonomic biases in the literature at family level by comparing the number of species per reptile or amphibian family present in the reviewed literature with a random expectation generated using the hypergeometric distribution (van Wilgen et al. 2010) in R v. 3.4.0 (R Development Core Team 2017). The hypergeometric distribution is similar to a binomial distribution and describes the probability of a given number of successes given a specified number of draws, without replacement. In this instance, a set number of species are sampled from a pool of families of known size. Families outside the $95 \%$ confidence intervals were deemed to be either over- or under-represented in the literature, compared to expectations based on the size of the family and the total number of species that appear in the literature. Results were visualised by plotting the number of species that have been described globally within each family against the proportion of species in the literature under review. We also 197 performed the same analysis at the level of herpetofaunal groups. 
199 Taxonomic bias was further assessed at herpetofaunal-group level by comparing information on

200 known invasions published in Kraus (2009), to information available from peer-reviewed

201 literature (this review). To provide a baseline of taxonomic and geographic scope of known

202 reptile and amphibian invasions, we used data from Kraus (2009), a database that details all

203 known introductions of non-native herpetofauna from the published and grey literature at the

204 time (2006/7). While these data are somewhat out of date, they represented the latest

205 comprehensive dataset of introduced and established species across taxa at the time and for the

206 purposes of our analysis we assume that derived ratios and trends will have remained similar.

207 Populations in the Kraus (2009) database are recorded at country, island or US-state level

208 (hereafter location). Any (or multiple) successful population(s) within a country or state is

209 counted as a successful introduction for that location (and the total number of introductions or

210 populations within a particular country or US state is not considered). We refer to "introduction"

211 as the arrival, outside of captivity, of a species in an area where it is not native (i.e. having

212 overcome a natural barrier to movement, Blackburn et al. 2011). Successful introductions

213 (established species) were classified according to Kraus (2009) as introductions "reported to be

214 established (within the country, island or US state) at the time of the most recent literature

215 citation for the population in question". "Established" is interpreted to mean a population that

216 has shown the ability to reproduce regularly, without human intervention (or in spite of human

217 interventions) to form populations of sufficient size to be resilient to stochastic events. From

218 Kraus (2009), we extracted the total number of species introduced anywhere outside of their

219 native range and the total number of known independent introductions per species per location

220 (some species may have been introduced to more than one country or US state) for each

221 herpetofaunal group. We then calculated the proportion of successfully established populations 
222 and species as a fraction of those introduced and as a fraction of all described species within the 223 group.

Potential geographic bias in the literature on non-native herpetofauna identified in this review was assessed at a crude level by comparing the number of studies for each country or US state with the number of successfully established species in that country (Kraus 2009). For multilocation studies, we scored only papers that truly collected/provided data for all localities defined within a region, and excluded studies which did not have a defined geographic scope or had clear geographical bias through selection of species (e.g. Kats \& Ferrer 2003; Pilliod, Griffiths \& Kuzmin 2012, where geographic scope was restricted by the example species selected) or areas (e.g. regional studies on reptile trade, such as Rataj et al. 2011 or Herrel \& van der Meijden 2014, where information was clearly not sourced from all countries or locales). A total of 800 papers for which exact country locations could be identified were included in this analysis. This included 22 papers deemed to be global in scope, for which all countries and US states were scored.

We also conducted a more detailed assessment of geographic coverage, extracting the species lists and locations from each paper and tallying the total number of species covered by each paper per location (country or state). The number of species studied was compared to the number of species established per location (Kraus 2009). Multi-location or global papers that dealt with more than one species were only included in this analysis in instances where it was possible to assign all the species in the paper to particular locations. Papers such as Bomford, Kraus, Barry 
244 \& Lawrence 2009 were therefore excluded as the paper did not specify whether the species used

245 in the models had been introduced to Britain, Florida or California. A total of 767 papers were

246 included in this analysis. All analyses were conducted in R v. 3.4.0 (R Development Core Team

247 2017), and maps produced in ARCMap 10.3.1 (ESRI 2015).

249 Results

Representation of herpetofaunal groups in the literature

251 Only 1116 species (6\% of c. 18145 described herpetofaunal species; Frost 2017; Uetz, Freed \&

252 Hošek 2017) are included in the 836 studies relating to herpetofaunal invasions in this review.

253 Five-hundred-and-fifty-two (49\%) of these species appear in only one study, and 909 species

254 (81\%) appear in fewer than 5 studies. Ninety-five percent of species were included in fewer than

255 twelve studies. Hardly any studies were conducted on non-native herpetofauna before 1990, and

256 most studies were published after 2000 (Supplementary Figure S1). A large proportion of papers

$257(653 / 836,78 \%)$ focused on a single species, and only a minority (54 or 6\%) reported on more

258 than 10 species.

260 Of the papers included in this review, most focus on or include frogs (58\%, Table 1), while

lizards appear in almost a quarter of studies. The remaining herpetofaunal groups are represented

262 in $18 \%$ or fewer of papers relating to non-native herpetofauna. However, frogs and lizards are

264 the literature actually under-represents these groups as a whole (Fig. 2a). Turtles and crocodiles are comparatively small herpetofaunal groups ( 25 crocodile species and 347 testudine species 
266 have been described to date) and have the most representative sample of species covered by the

267 literature. Both groups are overrepresented in the papers that were reviewed (Fig. 2a, 47\% and

$26856 \%$ of species from these respective groups occur in at least one of the papers included in this

269 review, Table 2), as are snakes.

271 Some families have received more attention than others. For reptiles, nearly all the testudine and

272 crocodilian families (e.g. Cheloniidae, Testudinidae, Emydidae, Alligatoridae, Crocodylidae) are

273 overrepresented in the literature, i.e. they have more species written about than expected by

274 chance given the size of the family, compared to reptiles as a whole (Fig. 2b). Snake families that

275 stand out include boids (Boidae and Pythonidae), Viperidae and Elapidae, while the lizard

276 families most overrepresented across studies are iguanids (Iguanidae and Corytophanidae),

277 varanids and chameleons. Over-represented amphibian families include three of the nine

278 salamander families (Ambystomatidae, Cryptobranchidae and Salamandridae), and nine out of

27956 frog families, including Ranidae, Pipidae, Dendrobatidae, Ceratophryidae and

280 Bombinatoridae (see Fig. 2c for these and others). Families might be under-represented in the

281 literature if (1) species in these families are being translocated without being reported, or if (2)

282 species in these families are genuinely not moved around, typically resulting in no or very few

283 non-native representatives for the group. The fleshbelly frogs (Craugastoridae, approximately

284800 species) were the largest amphibian family with no species present in the invasion ecology

285 literature. The largest reptile family with no representatives was the Uropeltidae (shieldtail

286 snakes, 54 species). 
288 There are a handful of well-studied species within each herpetofaunal group (Fig. 3). These

289 include the cane toad (Rhinella marina; 243 papers, or $29 \%$ of all papers focus on or include this

290 species), the American bullfrog (Lithobates catesbeianus; 130 papers), the red-eared slider

291 (Trachemys scripta; 95 papers), the brown tree-snake (Boiga irregularis; 57 papers), the African

292 clawed frog (Xenopus laevis; 51 papers) and the brown anole (Anolis sagrei; 41 papers, Fig. 3 \&

293 4). The best-studied salamander is the tiger salamander (Ambystoma tigrinum, 15 papers), and

294 the best-studied crocodilian is the spectacled caiman (Caiman crocodilus, 14 papers, Fig. 3 \& 4).

295 The literature on crocodiles, frogs and turtles is particularly skewed towards individual species.

296 Over half (59\%) of papers that include crocodiles focus on or include C. crocodilus, and half

$297(50 \%)$ of the literature on frogs is focussed on or includes the cane toad $R$. marina (while $L$.

298 catesbeianus appears in $27 \%$ of frog papers). The red-eared slider features in nearly three-

299 quarters (73\%) of literature on non-native turtles (Fig. 4). The literature on lizards is least

300 dominated by a single taxon, with the most well-represented species, $A$. sagrei, appearing in $21 \%$

301 of papers that cover non-native lizards (Fig. 4).

Subject focus of research

304

305

306

307

308

309

Most research (416 papers; 50\%) has been conducted on impacts (Fig. 4). A large portion of this impact literature (42\%), however, covers impacts of only two species, $R$. marina and $T$. scripta (Fig. 4). Similarly, the literature on control of non-native herpetofauna is heavily biased in favour of cane toads (included in $33 \%$ of papers on control) and brown tree-snakes (24\% of papers on control, Fig. 4), while cane toads appear in over a third of studies (39\%) on invasion correlates. There was no significant difference in the distribution of literature across subjects 
310 between papers that focussed on one species and papers that covered multiple species or which

311 made no specific mention of species $(\mathrm{V}=21, \mathrm{p}=0.7422)$.

314 Excluding the 22 global studies, which largely made use of the same information base as the

315 well-studied areas, the bulk of research on non-native herpetofauna covered in our review has

316 been conducted in Australia (217 studies), the United States (195 studies, mostly focussed on or

317 including Florida, 86 studies and California, 41 studies), Brazil (40 studies) and Spain (40

318 studies), as well as several islands or island groups such as Guam (47 studies), Hawaii (46

319 studies) and the greater Caribbean (47 studies), with very limited information from other

320 localities (Fig. 5). For example, the seven studies that were identified specifically from

321 continental Africa, were all conducted in South Africa.

323 We further compared the geographical distribution and frequency of literature on herpetofauna to

324 the distribution of documented introductions from Kraus (2009). One third (33\%) of the 600

325 species (nomenclature updated to match our list) included in the Kraus (2009) database have

326 been studied in fewer localities than they have been introduced (Table 3). Excluding non-

327 location-specific studies, only 8 countries, 5 oceanic islands/island states and 6 US states have

328 two or more location-specific studies per successful invasive amphibian or reptile introduction.

329 The majority of localities (79\%) where established populations have been recorded ( $\mathrm{n}=191: 145$

330 countries and 46 US states) have fewer than two location-specific studies (aside from global or

331 continental reviews) for every successful species (mean $=1.1)$, providing a poor basis on which 
332 to base their risk analyses. Only six of the 23 localities that have more than 10 established non-

333 native species, have more than two location-specific studies per successful species: Australia,

334 Guam, the United Kingdom, China (inclusive of studies in Taiwan), California and France.

336 Additional anomalies are apparent when considering the number of species covered in the 337 literature per location ( $\mathrm{n}=767$ studies, Fig. 5b). In South Africa, where only seven established 338 species have been recorded (Kraus 2009), 285 species are covered by the local literature (seven 339 studies, although the bulk of the species appear in a list of traded species), equating to 41 species 340 documented per successfully established non-native. For localities with more than 10 established 341 non-natives $(n=23)$, rates of study range from $<0.08$ species studied per successful species for

342 La Reunion, to $>3.5$ species studied per successful species in Texas, the United Kingdom,

343 Indonesia, Florida, China, Japan and the United States as a whole. The United States has the 344 highest recorded number of successfully established non-natives (108 species), covered at a rate 345 of four species studied per invasive species (451 species appear in the 192 papers that have a US 346 focus). In the case of China (25 studies, including Taiwan, that document 47 species, at 4.3

347 species studied per established species), the number of successfully established species (11) is 348 likely an underestimate (Liu, McGarrity \& Li 2012).

At a location level, there is clearly also selection towards studying certain species in particular places. For example, in Australia, where 28 established non-natives have been recorded (Kraus 352 2009), 91\% of studies focus on or include the cane toad. Similarly, $92 \%$ of the papers that 353 include Guam and the Mariana Islands dealt with or include the brown tree snake, and $44 \%$ of 
354 papers that include China focus on or include the American bullfrog. Of the five most widely

355 introduced species (Kraus 2009: T. scripta, 84 localities [countries/US states], the Brahminy

356 blind snake Indotyphlops braminus, 65 localities, L. catesbeianus, 58 localities, R. marina, 48

357 localities and the common house gecko Hemidactylus frenatus, 45 localities), only the American

358 bullfrog - studied in 27 countries and 18 US states - has been studied in at least three quarters of

359 the number of localities to which it has been introduced. The common house gecko (33\%) and

360 Brahminy blind snake (28\%) have been studied in a third or less of the number of introduction

361 locales.

362

363

Success of different herpetofaunal groups

364

365

366

367

368

369

370

371

372

373

374

According to the data contained in Kraus (2009), lizards and frogs have had the highest rates of successful establishment per species introduced (over 55\% of frogs and lizards introduced outside their native range have established in at least one location), while crocodiles (at 14\%) have the lowest (Table 2$)$. However, crocodiles and turtles $(\sim 27 \%$ of known species in both groups) have had the most representative sample of species introduced from their respective herpetofaunal groups (Fig. 2). It is therefore not surprising that turtles have the most representative sample of established or invasive species: $11.5 \%$ of all described turtles have successfully established somewhere outside their native range (Table 2). The proportion of successful non-native species is much lower for other groups (typically $1-2 \%$ and as low as $0.8 \%$ for snakes, Table 2). 
375 Despite the high rates of establishment for those lizards and frogs that have been introduced, the

376 low representation of species that have been introduced outside of their native ranges (according

377 to the literature on which Kraus 2009 is based) means that we know nothing about the invasive

378 potential of the $\sim 6200$ lizards and $\sim 6600$ frogs that have never been given the opportunity to

379 demonstrate their potential to establish or invade (Table 2).

\section{Discussion}

Our review of the herpetofaunal invasion literature identified 836 studies, covering 1116 species. A number of distinct taxonomic, geographic and subject patterns are highlighted. Most of the literature has been produced post-2000, with a strong focus on frogs (Table 1), particularly cane toads and their impacts in Australia. While comparatively less work has been conducted on turtles and snakes, proportionately more species from both these groups have been included in studies than is the case for frogs (Fig. 2). Most countries have very little peer-reviewed literature on non-native herpetofauna (fewer than two papers per established species). Africa and Asia, in particular have had very few studies, though for southern Africa at least, this is probably a realistic reflection of the small number of introductions and invasions (Measey et al. 2017). Interestingly, the role of trade in the introduction of non-native species has received little attention in the period under review, despite the obvious link between trade and invasion pathways for these groups (but see Garner, Stephen, Wombwell \& Fisher 2009). Although rates of establishment success are likely inflated by higher reporting of successful introductions, the remarkably high rates of establishment success [33\% for reptiles and amphibians introduced to Florida (Krysko et al. 2016), 25\% reported for vertebrates globally (Wilson 2016), and >50\% for

397 lizards and frogs (Table 2; Kraus 2009)], make trade regulation and pre-border risk assessment 
398

399

400

401

402

403

404

405

406

407

408

409

410

411

412

413

414

415

416

417

418

419

very important management components for these species. As of 2017, research on trade of nonnative herpetofauna appears to be expanding (e.g. García-Díaz, Ross, Woolnough \& Cassey 2017; Measey 2017).

Geographic and taxonomic biases in the literature are well known for most groups of invasive species (Dawson et al. 2017), and we expect research effort to be concentrated in areas and on species that have the biggest impacts. However, while research effort has been largely appropriate, understanding the extent of existing biases is crucial for predicting and preventing future invasions and their likely impacts, especially if for most places and most species, the number of studies is insufficient. For example, half of the work on frogs has been conducted on the cane toad and nearly all the work on the cane toad (86\%) has been conducted in Australia, meaning that despite a massive literature, this species' potential impacts on mammals, aside from marsupials, remains largely unstudied. At the same time, less well-studied species like the Asian toad (Duttaphrynus melanostictus) are scored as having high potential impact as a result of areaspecific cultural traits, such as eating toads that has resulted in poisoning of people (see Measey et al. 2016), although not necessarily applicable in areas where frogs are not routinely eaten.

\section{Taxonomic biases}

While few non-native herpetofaunal taxa have been studied in comparison to species from other groups (Dawson et al. 2017), the bias in studies on non-native herpetofauna is similar to the bias in information on native species. Less than half (40\%) of reptile species have had their conservation status assessed (Bland \& Böhm 2016; Meiri \& Chapple 2016). Those families with 
420 the fewest conservation assessments included either families with no species identified in this

421 review, or families that were under-represented (e.g. Amphisbaenidae). With the exception of

422 Opluridae (Madagascan iguanas), from which no species were identified in our review, those

423 families with the most conservation assessments (Meiri \& Chapple 2016) were identified to be

424 either over-represented (Iguanidae) or proportionately represented (neither over nor

425 underrepresented, e.g. Crotaphytidae, Phrynosomatidae) in the invasion literature. Amphibians,

426 on the other hand, have all been assessed through The Global Amphibian Assessment (Stuart et

427 al. 2004). All families identified through the global assessment to be threatened by over-

428 exploitation (for at least one species in the family, Stuart et al. 2004) were also found to be well-

429 or over-represented in the invasion literature (e.g. Leptodactylidae, Ranidae, Dendrobatidae,

430 Microhylidae, Ambystomatidae, Salamandridae, Cryptobranchidae, Fig. 2), highlighting that

431 families or species that are used by people are more likely to become invasive.

For plants, grasses are an example of a huge family with many known invasive species. Yet only 434 a tiny portion have been assessed to determine the extent of introduction to new localities and the level of establishment and invasion (Visser et al. 2016). Focussing on functional (e.g. Canavan et 436 al. 2018) or taxonomic groups (e.g. Canavan et al. 2017) has allowed scientists to distinguish 437 syndromes of traits that enhance invasiveness. For herpetofauna, we suggest that a useful 438 approach is to classify relevant functional groups of invaders and identify traits within these 439 groups that correlate with invasive success (Allen, Street \& Capellini, 2017; Tingley et al. 2010).

440 For example, there is likely a difference in invasion correlates for species that are intentionally 441 introduced (e.g. via the pet trade) and those that tend to move around as 'hitch-hiker' species 442 (Kraus 2007). Some groups, despite their large size, are absent from the invasion literature 
443 because no species have been introduced to localities outside their native range. For example,

444 families that do not make good pets (e.g. snakes from the family Uropeltidae, Fig. 2) and/or are

445 unlikely to be transported accidentally (e.g. groups that have small, remote distributions and very

446 specialised habitat). Other families appear to be over-represented in the invasion literature. For

447 example, nearly all testudine families are overrepresented. This makes sense because tortoises

448 and turtles are popular pets and are therefore widely traded and documented outside of their

449 native ranges. The dominance of the red-eared slider in the literature, however, suggests that

450 although testudines in general are exceptionally widely traded, proportionately fewer species

451 actually become invasive or have notable impacts. Red-eared sliders are traded in vast numbers

452 (common estimates are upward of 3 million hatchlings traded globally on an annual basis,

453 Ramsay, Ng, O’Riordan \& Chou 2007). Reducing the volume of this trade could be achieved by

454 enforcing stricter controls on animal husbandry and trade, and encouraging the public to be more

455 responsible pet keepers (Williams 1999).

457 Geographic biases

458 For the large majority of countries, especially in Africa, where little information is available, 459 there are few known established non-native species and few studies. There are, however, also 460 countries where despite several (e.g. Egypt, Greece) or many (e.g. Japan, Indonesia) established 461 species, very few studies have been conducted (Fig. 5c). For Japan and Indonesia, at least, the 462 studies that have been conducted have covered a broader range of species than are known to be 463 established (Fig. 5b). Peer-reviewed studies from these two countries, along with others like the 464 United Kingdom, New Zealand and South Africa have covered many more species than are 465 currently established (Fig 5b). The reason for this is not always clear, but could be due to a keen 
466 interest in herpetology in these areas or proactive research into trade and/or risk assessment (e.g.

467 Goka, Okabe \& Takano 2013; Chapple, Knegtmans, Kikillus \& van Winkel 2016).

468

469 In other locations, such as Australia and Guam, the peer-reviewed literature generation has been

470 prolific (Fig. 5a), but focussed on single species. This means that although Australia has the most

471 peer-reviewed literature (Fig. 5a) and the most papers produced per invasive species (Fig. 5c),

472 most of the species that are established in Australia are still understudied (Fig. 5b). With the

473 exception of a few places such as Florida where there is significant interest in the high numbers

474 of invasions that appear to be driven by a large number of ports, a well-developed trade in exotic

475 pets, and high levels of environmental disturbance (Krysko et al. 2016); the United Kingdom,

476 which has a large number of English-language academic hubs; and Brazil, the bias is worse for

477 the rest of the globe. This likely reflects a lack of research capacity where there are invasions that

478 are not reported or studied. For example, there are almost no studies or invasions recorded for

479 Africa. This could be the result of fewer introductions and/or a capacity gap in herpetologists to

480 report invasions. In other instances (e.g. China and Russia), it is possible that both invasions and

481 literature on them have gone undetected because documentation regarding these events are not

482 available in English, and therefore not searchable using the Web of Science (Adam 2002).

483 Records of first introductions for reptiles show exponential growth since about the 1950s, with

484 no end in sight to this trend (Seebens et al. 2017). While there are likely already many

485 undetected invasions, new areas remain vulnerable and increased awareness is important for

486 preventing future invasions. 


\section{Setting priorities}

489 Countries like New Zealand that have focussed on allowing importation and trade in only a short

490 list of permitted species appear to have achieved the highest success in reducing introductions

491 (Genovesi, Carboneras, Vilà \& Walton 2015; Seebens et al. 2017). The current trend for

492 assessing which species should be permitted on such lists is to quantify the impacts of the species

493 based on published information. This begs the question: How many publications are needed to

494 provide adequate information to allow for the accurate assessment of risk of invasiveness and

495 impact? This is not an easily quantifiable number, but we can gain some insights using recent

496 EICAT assessments and their confidence levels to suggest numbers. Without directed research,

497 only 265 of 365 papers on 39 invasive amphibians had impacts that could be scored using the

498 EICAT scheme (Kumschick et al. 2017). Of these, only 8 species could be rated with high

499 confidence for at least one impact mechanism and no species was rated with high confidence on

500 more than one impact mechanism (EICAT scores 12 impacts, of which 8 are applicable to

501 reptiles and amphibians: Predation, Poisoning/Toxicity, Competition, Hybridization, Disease

502 Transmission, Interaction with other species, Parasitism, and Grazing/Herbivory/Browsing).

503 Given that these 8 species include the five most commonly studied frogs and salamanders (see

504 Fig. 2b\&d), we might conclude that even hundreds of studies are not sufficient to produce high-

505 confidence scores on each impact mechanism for EICAT (ignoring SEICAT impacts). However,

506 one study is capable of producing high confidence on one impact mechanism. Two such

507 examples of species that were rated highly on confidence with just a single study: Dubey,

508 Leuenberger \& Perrin (2014) on hybridisation in Italian water frogs (Pelophylax bergeri) and

509 Holsbeek et al. (2010) on hybridisation with Levant water frogs (P. bedriagae). This suggests

510 that with more work focussed on such impact assessments, total impact for EICAT may be 
511 assessed with a minimum of 8 papers, relating to each of the impact mechanisms in Hawkins et

512 al. (2015, see above). To date, no EICAT assessment has found a comprehensive literature for

513 any invasive species (Evans, Kumschick \& Blackburn 2016). From our work, we know that a

514 minority of invasive herpetofaunal species have been the focus of any research. Clearly, much

515 more directed work is needed.

516

517 Our study revealed that the majority of publications (78\%) focus on single species, and that a

518 large proportion of these, and other studies in this review (50\%) concern impacts, which is good

519 news for those hoping to score EICAT and SEICAT for these species. However, we caution that

520 risk assessments require a fuller understanding of the invasive species, and that studies on

521 pathways (11\%) and trade (2\%) are particularly poorly represented (Fig. 3$)$. Given the

522 importance of the first in risk assessment and the volume and key role of the latter in

523 introductions (García-Díaz, Ross, Woolnough \& Cassey 2017), we emphasise the need for more

524 strategic publications analysing the trade in herpetofauna and other pathways related to their

525 unintentional movement (Tingley et al. 2018).

527 The Global Amphibian Assessment is a good example of a world-wide initiative that drove

528 substantial work to collate information for all species to provide a baseline and a fantastic

529 resource for refining data. Given that only a small portion of herpetofauna currently appear to be

530 moved around in high numbers, or show invasive tendencies, setting up more global initiatives to

531 focus on groups of invaders across a broader geographic range is not an unrealistic task,

532 particularly considering that distribution information is already available for amphibians. 
533 Initiatives for invaded countries to work together on the impacts of common invasive taxa could

534 provide an important platform for accumulating crucial information on impacts. One such

535 initiative in Europe saw members from four EU countries funded to work jointly on the impacts

536 of the invasive African clawed frog, X. laevis: INVAXEN

537 (http://www.anthonyherrel.fr/INVAXEN/). This initiative has added 15 published articles on this

538 species, nearly doubling the available data on their invasive populations (e.g. Courant et al. 2017;

539 Louppe, Courant \& Herrel 2017; Rödder et al. 2017). Funded by BIODIVERSA, this call did not

540 include funding for studies on populations in non-participating EU countries (e.g. Italy), or in the

541 native range of the species in southern Africa. There is scope for similar work on species like the

542 red-eared slider, and other turtles that are currently studied in fewer locations than which they

543 have been introduced (e.g. European pond turtles, Emys orbicularis and common snapping

544 turtles Chelydra serpentina), several widespread gecko species, agamids like oriental garden

545 lizards (Calotes versicolor), the Asian toad, and selected species from the families that are

546 overrepresented in the literature and trade or even the cane toad outside of Australia.

548 Local and regional herpetological societies have a crucial role to play in this regard and should

549 be encouraged to publish all new records of reptiles and amphibians in online databases and

550 society websites. Many societies already do record such information in newsletters, but digitizing

551 these data and making them available online could go a long way to improving the geographic

552 coverage of literature and even reducing the taxonomic bias in published information. McGeoch

553 et al. (2016) provide a protocol for prioritizing species, pathways and sites to assist countries in

554 meeting Aichi Biodiversity Targets (Convention on Biological Diversity). Herpetological

555 societies should contribute relevant information to the Global Register of Introduced and 
556 Invasive Species (GRIIS) currently under development within the Global Invasive Alien Species

557 Partnership (GIASIP) framework (McGeoch et al. 2016). In the absence of information, risk

558 assessments will continue to rely on information from models based on well-studied species.

559 Improving the geographic coverage of studies on model organisms and then the taxonomic

560 coverage of model taxa will go a long way to improving predictions for invasive species and

561 ultimately reducing their impacts.

562

563 Acknowledgements

$564 \mathrm{R}$ code for calculating the hypergeometric distributions was adapted from code originally written

565 by John Wilson. We thank several reviewers who improved the clarity and content of earlier

566 versions of this manuscript.

567

568 Funding statement

569 This work was supported by the DST-NRF Centre of Excellence for Invasion Biology and the

570 National Research Foundation of South Africa (grant 85417 to DMR and grant 87759 to JM).

571

572 Supplementary information

573 Details of the research areas excluded from the ISI search during the systematic review, and an

574 additional figure illustrating the accumulation of studies on non-native reptiles and amphibians

575 over time are available in the Supplementary Material, S1. Details of the 823 papers included in

576 the systematic review are provided in the Supplementary Material, S2. The raw data include the 
577 names of each species covered by each paper as well as the geographic scope (at country level)

578 of each paper.

579 
580

581

582

583

584

585

586

587

588

589

590

591

592

593

594

595

596

597

598

599

600

601

602

603

604

605

606

607

608

609

610

611

612

613

614

615

616

617

618

619

620

621

622

623

624

\section{References}

Adam, D. (2002) The counting house. Nature, 415, 726-729.

Allen, W.L., Street, S.E. \& Capellini, I. (2017) Fast life history traits promote invasion success in amphibians and reptiles. Ecology Letters, 20, 222-230.

Bacher, S., Blackburn, T.M., Essl, F., Genovesi, P., Heikkilä, J., Jeschke, J.M., . . Ramula, S. (2018) Socio-economic impact classification of alien taxa (SEICAT). Methods in Ecology and Evolution, 9, 159-168.

Blackburn, T.M., Essl, F., Evans, T., Hulme, P.E., Jeschke, J.M., Kuhn, I., . . Bacher, S. (2014) A unified classification of alien species based on the magnitude of their environmental impacts. PLoS Biology, 12, e1001850, https://doi.org/10.1371/journal.pbio.1001850.

Blackburn, T.M., Pyšek, P., Bacher, S., Carlton, J.T., Duncan, R.P., Jarošík, V., . . Richardson, D.M. (2011) A proposed unified framework for biological invasions. Trends in Ecology and Evolution, 26, 333-339.

Bland, L.M. \& Böhm, M. (2016) Overcoming data deficiency in reptiles. Biological Conservation, 204, 16-22.

Bomford, M., Kraus, F., Barry, S.C. \& Lawrence, E. (2009) Predicting establishment success for alien reptiles and amphibians: a role for climate matching. Biological Invasions, 11, 713724.

Canavan, S., Pyšek, P., Packer, J.G., Meyerson, L.A., Richardson, D.M., Visser, V., ... Wilson, J.R.U. (2018) Tall-statured grasses: a useful functional group for invasion science? Biological Invasions https://doi.org/10.1007/s10530-018-1815-z.

Canavan, S., Richardson, D.M., Visser, V., Le Roux, J.J., Vorontsova, M.S. \& Wilson, J.R.U. (2017) The global distribution of bamboos: assessing correlates of introduction and invasion. AoB Plants, 9, plw078. doi: 010.1093/aobpla/plw1078.

Chapple, D.G., Knegtmans, J., Kikillus, H. \& van Winkel, D. (2016) Biosecurity of exotic reptiles and amphibians in New Zealand: building upon Tony Whitaker's legacy. Journal of the Royal Society of New Zealand, 46, 66-84.

Courant, J., Vogt, S., Marques, R., Measey, J., Secondi, J., Rebelo, R., . . . Backeljau, T. (2017) Are invasive populations characterized by a broader diet than native populations? PeerJ, 5, e3250.

Dawson, W., Moser, D., Kleunen, M.v., Kreft, H., Pergl, J., Pyšek, P., . . Essl, F. (2017) Global hotspots and correlates of alien species richness across taxonomic groups. Nature Ecology and Evolution, 1, DOI: 10.1038/s41559-41017-40186 | www.nature.com/natecolevol.

Dubey, S., Leuenberger, J. \& Perrin, N. (2014) Multiple origins of invasive and 'native'water frogs (Pelophylax spp.) in Switzerland. Biological Journal of the Linnean Society, 112, 442-449.

ESRI (Environmental Systems Research Institute). (2015) ArcGIS Release 10.3.1. Redlands, CA.

Evans, T., Kumschick, S. \& Blackburn, T.M. (2016) Application of the Environmental Impact Classification for Alien Taxa (EICAT) to a global assessment of alien bird impacts. Diversity and Distributions, 22, 919-931.

Ferreira, R.B., Beard, K.H., Peterson, S.L., Poessel, S.A. \& Callahan, C.M. (2012) Establishment of introduced reptiles increases with the presence and richness of native congeners. Amphibia-Reptilia, 33, 387-392. 
625

626

627

628

629

630

631

632

633

634

635

636

637

638

639

640

641

642

643

644

645

646

647

648

649

650

651

652

653

654

655

656

657

658

659

660

661

662

663

664

665

666

667

668

669

Frost, D.R. (2017) Amphibian Species of the World: an Online Reference. Version 6.0.

Electronic Database accessible at http://research.amnh.org/herpetology/amphibia/index.html. Accessed: February 2017.American Museum of Natural History, New York, USA.

Fujisaki, I., Hart, K.M., Mazzotti, F.J., Rice, K.G., Snow, S. \& Rochford, M. (2009) Risk assessment of potential invasiveness of exotic reptiles imported to south Florida. Biological Invasions, 12, 2585-2596.

Garcia-Diaz, P., Ross, J.V., Ayres, C. \& Cassey, P. (2015) Understanding the biological invasion risk posed by the global wildlife trade: propagule pressure drives the introduction and establishment of Nearctic turtles. Global Change Biology, 21, 1078-1091.

García-Díaz, P., Ross, J.V., Woolnough, A.P. \& Cassey, P. (2017) The illegal wildlife trade is a likely source of alien species. Conservation Letters, 10, 690-698.

Garner, T.W.J., Stephen, I., Wombwell, E. \& Fisher, M.C. (2009) The amphibian trade: bans or best practice? Ecohealth, 6, 148-151.

Genovesi, P., Carboneras, C., Vilà, M. \& Walton, P. (2015) EU adopts innovative legislation on invasive species: a step towards a global response to biological invasions? Biological Invasions, 17, 1307-1311.

Goka, K., Okabe, K. \& Takano, A. (2013) Recent cases of invasive alien mites and ticks in Japan: why is a regulatory framework needed? Experimental and Applied Acarology, 59, 245-261.

Hawkins, C.L., Bacher, S., Essl, F., Hulme, P.E., Jeschke, J.M., Kuhn, I., . . Blackburn, T.M. (2015) Framework and guidelines for implementing the proposed IUCN Environmental Impact Classification for Alien Taxa (EICAT). Diversity and Distributions, 21, 13601363.

Holsbeek, G., Mergeay, J., Volckaert, F.A.M. \& De Meester, L. (2010) Genetic detection of multiple exotic water frog species in Belgium illustrates the need for monitoring and immediate action. Biological Invasions, 12, 1459-1463.

Hulme, P.E. (2013) Weed risk assessment: a way forward or a waste of time? Journal of Applied Ecology, 49, 10-19.

Kats, L.B. \& Ferrer, R.P. (2003) Alien predators and amphibian declines: review of two decades of science and the transition to conservation. Diversity and Distributions, 9, 99-110.

Kraus, F. (2007) Using pathway analysis to inform prevention strategies for alien reptiles and amphibians. Managing Vertebrate Invasive Species, 21, 94-103.

Kraus, F. (2009) Alien reptiles and amphibians · a scientific compendium and analysis. Springer, Dordrecht, The Netherlands.

Kraus, F. (2015) Impacts from Invasive Reptiles and Amphibians. Annual Review of Ecology, Evolution, and Systematics, 46, 75-97.

Krysko, K.L., Burgess, J.P., Rochford, M.R., Gillette, C.R., Cueva, D., Enge, K.M., ... Nielsen, S.V. (2011) Verified non-indigenous amphibians and reptiles in Florida from 1863 through 2010: Outlining the invasion process and identifying invasion pathways and stages. Zootaxa, 1-64.

Krysko, K.L., Somma, L.A., Smith, D.C., Gillette, C.R., Cueva, D., Wasilewski, J.A., . . . Warren, A. (2016) New verified nonindigenous amphibians and reptiles in Florida through 2015, with a Summary of over 152 years of introductions. IRCF Reptiles and Amphibians, 23, 110-143. 
670

671

672

673

674

675

676

677

678

679

680

681

682

683

684

685

686

687

688

689

690

691

692

693

694

695

696

697

698

699

700

701

702

703

704

705

706

707

708

709

710

711

712

713

714

Kumschick, S., Bacher, S., Evans, T., Markova, Z., Pergl, J., Pyšek, P., . . Nentwig, W. (2015) Comparing impacts of alien plants and animals in Europe using a standard scoring system. Journal of Applied Ecology, 52, 552-561.

Kumschick, S. \& Richardson, D.M. (2013) Species-based risk assessments for biological invasions: advances and challenges. Diversity and Distributions, 19, 1095-1105.

Kumschick, S., Vimercati, G., de Villiers, F.A., Mokhatla, M.M., Davies, S.J., Thorp, C.J., . . . Measey, G.J. (2017) Impact assessment with different scoring tools: How well do alien amphibian assessments match? NeoBiota, 33, 53-66.

Liu, X., McGarrity, M.E. \& Li, Y. (2012) The influence of traditional Buddhist wildlife release on biological invasions. Conservation Letters, 5, 107-114.

Louppe, V., Courant, J. \& Herrel, A. (2017) Differences in mobility at the range edge of an expanding invasive population of Xenopus laevis in the west of France. Journal of Experimental Biology, 220, 278-283.

Mahoney, P. J., Beard, K. H., Durso, A. M., Tallian, A. G., Long, A. L., Kindermann, R. J., Nolan, N. E., Kinka, D. \& Mohn, H. E. (2015) Introduction effort, climate matching and species traits as predictors of global establishment success in non-native reptiles. Diversity and Distributions, 21: 64-74.

McGeoch, M.A., Genovesi, P., Bellingham, P.J., Costello, M.J., McGrannachan, C. \& Sheppard, A. (2016) Prioritizing species, pathways, and sites to achieve conservation targets for biological invasion. Biological Invasions, 18, 299-314.

Measey, G., Vimercati, G., Villiers, F., Mokhatla, M., Davies, S., Thorp, C., . . Kumschick, S. (2016) A global assessment of alien amphibian impacts in a formal framework. Diversity and Distributions, 22, 970-981.

Measey, J. (2017) Where do African clawed frogs come from? An analysis of trade in live Xenopus laevis imported into the USA. Salamandra, 53, 398-404.

Measey, J., Davies, S.J., Vimercati, G., Rebelo, A., Schmidt, W. \& Turner, A. (2017) Invasive amphibians in southern Africa: A review of invasion pathways. Bothalia - African Biodiversity \& Conservation, 47, a2117.

Meiri, S. \& Chapple, D.G. (2016) Biases in the current knowledge of threat status in lizards, and bridging the 'assessment gap'. Biological Conservation, 204, 6-15.

Nentwig, W., Bacher, S., Pyšek, P., Vila, M. \& Kumschick, S. (2016) The generic impact scoring system (GISS): a standardized tool to quantify the impacts of alien species. Environmental Monitoring and Assessment, 188, 13.

Pheloung, P.C., Williams, P.A. \& Halloy, S.R. (1999) A weed risk assessment model for use as a biosecurity tool evaluating plant introductions. Journal of Environmental Management, 57, 239-251.

Pilliod, D.S., Griffiths, R.A. \& Kuzmin, L.S. (2012) Ecological Impacts of Non-Native Species. Amphibian Biology, Vol 10: Conservation and Decline of Amphibians: Ecological Aspects, Effect of Humans, and Management (eds H. Heatwole \& J.W. Wilkinson), pp. 3343-3382. Surrey Beatty \& Sons, Baulkham Hills, NSW, Australia.

Pimentel, D. (2011) Biological Invasions: Economic and environmental costs of alien plant, animal, and microbe species, second edition. CRC Press, New York.

Poessel, S.A., Beard, K.H., Callahan, C.M., Ferreira, R.B. \& Stevenson, E.T. (2013) Biotic acceptance in introduced amphibians and reptiles in Europe and North America. Global Ecology and Biogeography, 22, 192-201. 
715

716

717

718

719

720

721

722

723

724

725

726

727

728

729

730

731

732

733

734

735

736

737

738

739

740

741

742

743

744

745

746

747

748

749

750

751

752

753

754

755

756

757

758

759

760

Pyšek, P., Richardson, D.M., Pergl, J., Jarošík, V., Sixtová, Z. \& Weber, E. (2008) Geographical and taxonomic biases in invasion ecology. Trends in Ecology and Evolution, 23, 237-244.

Rago, A., While, G.M. \& Uller, T. (2012) Introduction pathway and climate trump ecology and life history as predictors of establishment success in alien frogs and toads. Ecology and Evolution, 2, 1437-1445.

Ramsay, N.F., Ng, P.K.A., O’Riordan, R.M. \& Chou, L.M. (2007) The red-eared slider (Trachemys scripta elegans) in Asia: a review. Biological invaders in inland waters: Profiles, distribution, and threats (ed. F. Gherardi), pp. 161-174. Springer, Dordrecht, The Netherlands.

Rataj, A.V., Lindtner-Knific, R., Vlahovic, K., Mavri, U. \& Dovc, A. (2011) Parasites in pet reptiles. Acta Veterinaria Scandinavica, 53, 33.

Richardson, D.M., Pyšek, P., Rejmánek, M., Barbour, M.G., Panetta, F.D. \& West, C.J. (2000) Naturalization and invasion of alien plants: concepts and definitions. Diversity and Distributions, 6, 93-107.

Rodda, G.H., Sawai, Y., Chiszar, D. \& Tanaka, H. (1999) Problem Snake Management: The Habu and the Brown Treesnake. pp. 534 pages. Cornell University, New York.

Rödder, D., Ihlow, F., Courant, J., Secondi, J., Herrel, A., Rebelo, R., . . . De Busschere, C. (2017) Global realized niche divergence in the African clawed frog Xenopus laevis. Ecology and Evolution, 7, 4044-4058.

Seebens, H., Blackburn, T.M., Dyer, E.E., Genovesi, P., Hulme, P.E., Jeschke, J.M., .. . Essl, F. (2017) No saturation in the accumulation of alien species worldwide. Nature Communications, 8, 9.

Shine, R. (2014) A review of ecological interactions between native frogs and invasive cane toads in Australia. Austral Ecology, 39, 1-16.

Speek, T.A.A., Davies, J.A.R., Lotz, L.A.P. \& van der Putten, W.H. (2013) Testing the Australian Weed Risk Assessment with different estimates for invasiveness. Biological Invasions, 15, 1319-1330.

Springborn, M., Romagosa, C.M. \& Keller, R.P. (2011) The value of nonindigenous species risk assessment in international trade. Ecological Economics, 70, 2145-2153.

Stringham, O.C. \& Lockwood, J.L. (2018) Pet problems: Biological and economic factors that influence the release of alien reptiles and amphibians by pet owners. Journal of Applied Ecology. https://doi.org/10.1111/1365-2664.13237

Stuart, S.N., Chanson, J.S., Cox, N.A., Young, B.E., Rodrigues, A.S.L., Fischman, D.L. \& Walle, R.W. (2004) Status and trends of amphibian declines and extinctions worldwide. Science, 306, 1783-1786.

R Core Development Team. (2017) R: A language and environment for statistical computing. R Foundation for Statistical Computing. Vienna, Austria.

Tingley, R., Romagosa, C.M., Kraus, F., Bickford, D., Phillips, B.L. \& Shine, R. (2010) The frog filter: amphibian introduction bias driven by taxonomy, body size and biogeography. Global Ecology and Biogeography, 19, 496-503.

Tingley, R., Phillips, B.L. \& Shine, R. (2011) Establishment success of introduced amphibians increases in the presence of congeneric species. American Naturalist, 177, 382-388.

Tingley, R., García-Díaz, P., Arantes, C.R.R. \& Cassey, P. (2018) Integrating transport pressure data and species distribution models to estimate invasion risk for alien stowaways. Ecography, 41, 635-646.

Uetz, P., Freed, P. \& Hošek, J. (2017) The Reptile Database, http://www.reptile-database.org. 
761

762

763

764

765

766

767

768

769

770

771

772

773

774

775

776

777

van Wilgen, N.J., Elith, J., Wilson, J.R., Wintle, B.A. \& Richardson, D.M. (2010) Alien invaders and reptile traders: What drives the live animal trade in South Africa? Animal Conservation, 13 (Supplement 1), 24-32.

van Wilgen, N.J. \& Richardson, D.M. (2012) The roles of climate, phylogenetic relatedness, introduction effort, and reproductive traits in the establishment of non-native reptiles and amphibians. Conservation Biology, 26, 267-277.

van Wilgen, N.J., Roura-Pascual, N. \& Richardson, D.M. (2009) A quantitative climate-match score for risk-assessment screening of reptile \& amphibian introductions. Environmental Management, 44, 590-607.

Visser, V., Wilson, J.R.U., Fish, L., Brown, C., Cook, G.D. \& Richardson, D.M. (2016) Much more give than take: South Africa as a major donor but infrequent recipient of invasive non-native grasses. Global Ecology and Biogeography, 25, 679-692.

Westgate, M.J. \& Lindenmayer, D.B. ( 2017) The difficulties of systematic reviews. Conservation Biology, 31, 1002-1007.

Williams, T. (1999) The Terrible Turtle Trade. Audubon 44, 101.

Wilson, E.O. (2016) Half-earth: Our planet's fight for life. Liveright Publishing Corporation, New York. 


\section{Figure 1 (on next page)}

\section{Prisma flowchart}

Prisma flow diagram (from Moher D, Liberati A, Tetzlaff J, Altman DG, The PRISMA Group (2009) Preferred Reporting Items for Systematic Reviews and Meta-Analyses: The PRISMA Statement. PLoS Med 6(7): e1000097. https://doi.org/10.1371/journal.pmed.1000097) for systematic review of articles on invasive amphibians and reptiles from the Web of Science (formerly Science Citation Index) on 3 March 2016. Search criteria used: Topic = alien OR invasive OR non-native OR exotic OR non-indigenous OR feral AND Topic= reptil* OR amphibia* OR turtle* OR tortoise* OR lizard* OR herpetofauna OR crocod* OR anura OR caudata OR testudin* OR ophidia OR sauria OR squamata OR snake* OR frog* OR toad* OR salamand* OR newt* 


\section{PRISMA 2009 Flow Diagram}

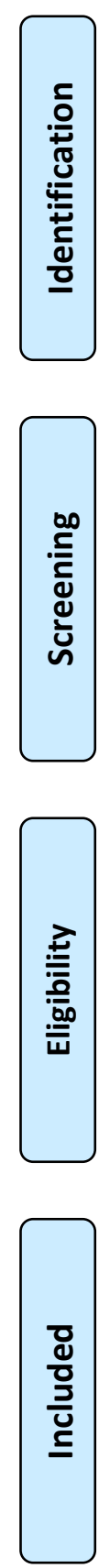

$$
\begin{aligned}
& \text { Records identified through } \\
& \text { database searching } \\
& (n=3194)
\end{aligned}
$$

Additional records identified through other sources

$(n=0)$

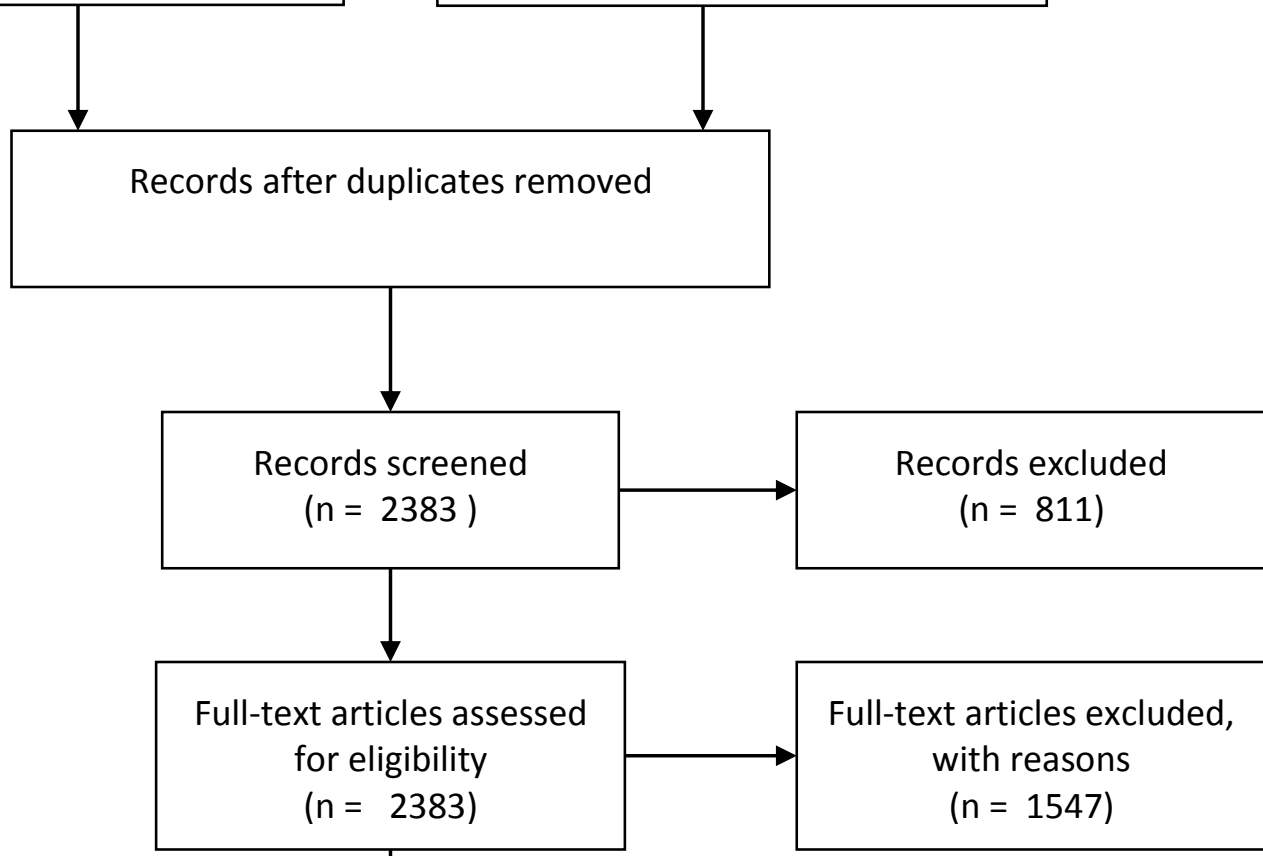

Studies included in

qualitative synthesis

$(n=836)$ 


\section{Figure 2 (on next page)}

Patterns in taxonomic representation of (a) herpetofaunal groups and (b) reptile and (c) amphibian families present in the invasion ecology literature.

Patterns in taxonomic representation of (a) herpetofaunal groups and (b) reptile and (c) amphibian families present in the invasion ecology literature. The median (middle green line) and $95 \%$ confidence intervals (brown lines), adjusted for multiple comparisons, were estimated from the hypergeometric distribution. The points represent herpetofaunal groups or families; those that fall between the brown lines are not significantly over or underrepresented (relative to amphibians or reptiles as a whole). Where multiple points overlap, lines indicate the number of points at each location. 
(a)

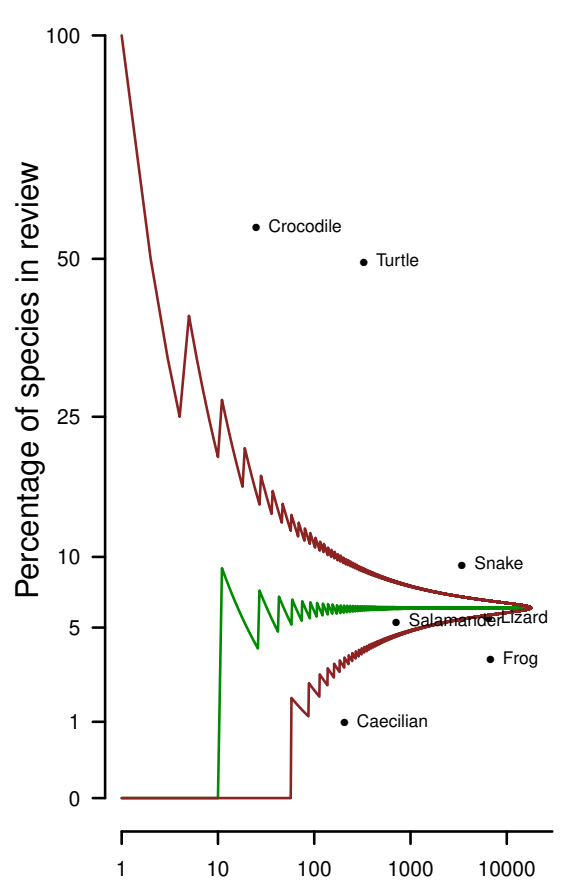

Number of species world-wide (b)

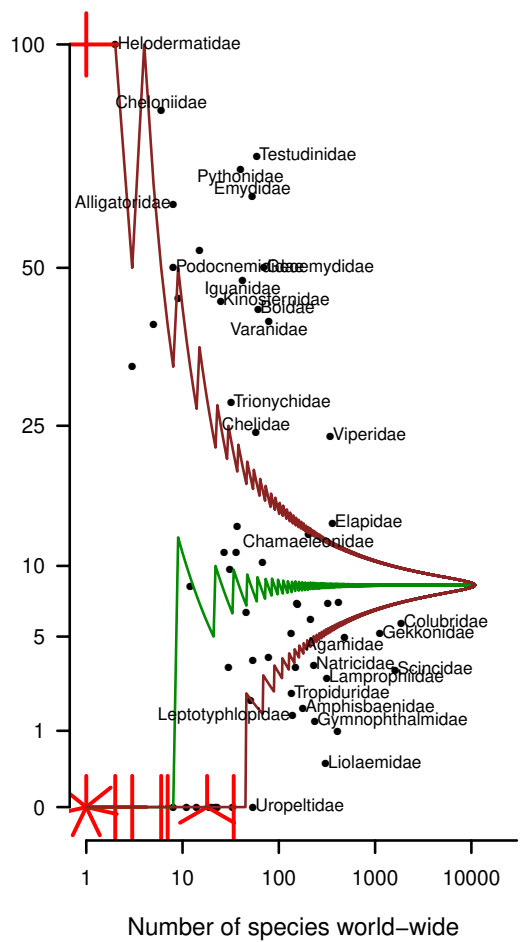

(c)

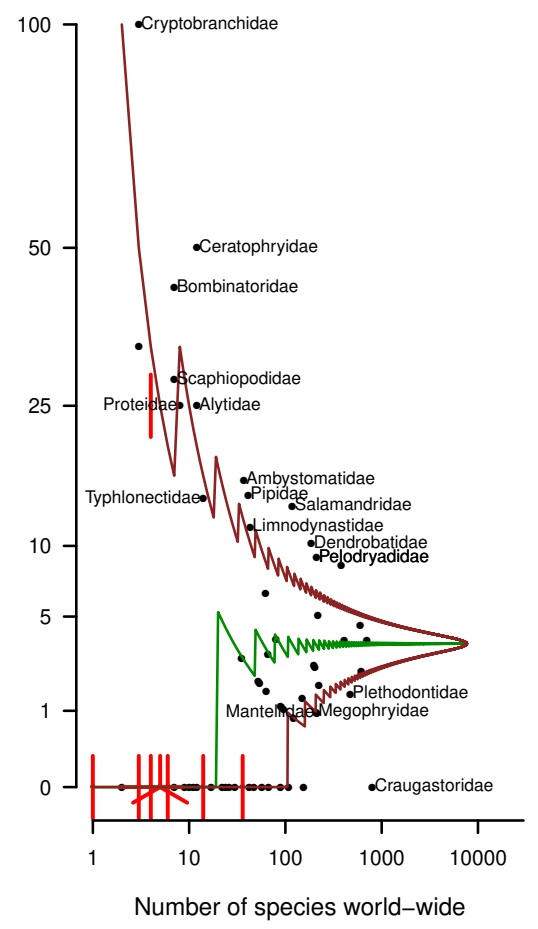




\section{Figure 3 (on next page)}

Number of articles per species of functionally-grouped amphibians and reptiles on the Web of Science.

Density plots show that the number of articles per species of functionally-grouped amphibians and reptiles on the Web of Science is always highly skewed toward one or two taxa, with the majority of species featuring only in one article. Taxa featuring in the highest number of articles have been highlighted for each group. 
PeerJ
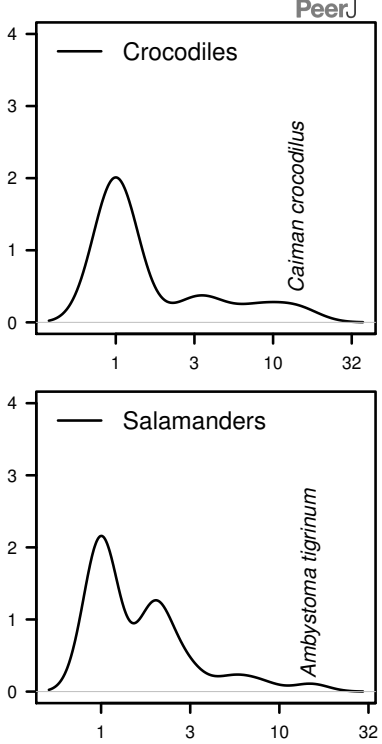

Manuscript to be reviewed
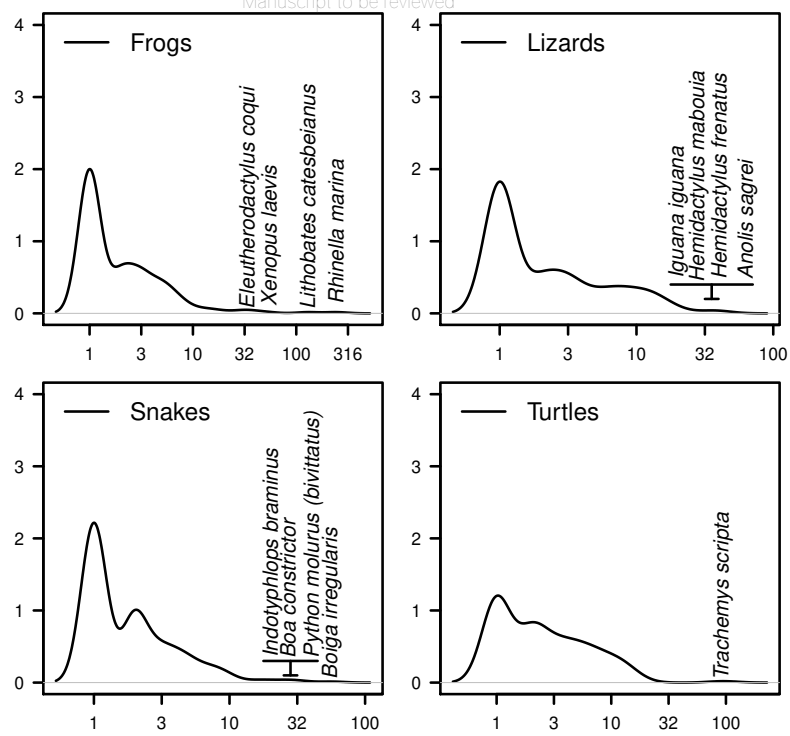

Number Nffpapers (log scale) 


\section{Figure 4 (on next page)}

Subject of literature on non-native amphibians and reptiles for each herpetofaunal group and across all species.

Composition of subject of literature on non-native amphibians and reptiles for each herpetofaunal group and across all species. In each group, literature on the most frequently studied species (Crocodiles Caiman crocodilus; Frogs Rhinella marina; Lizards Norops sagrei; Salamanders Ambystoma tigrinum; Snakes Boiga irregularis; and Turtles Trachemys scripta) is shown in black, showing that the knowledge of most non-natives comes from single taxa. For example, almost all papers on non-native turtles include or focus on Trachemys scripta. (Note each of the studies listed may have been included in more than one subject category as appropriate). 
${ }^{8}$ Pejerd Caiman crocodilus

6 Crocodiles
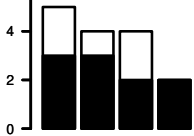

100

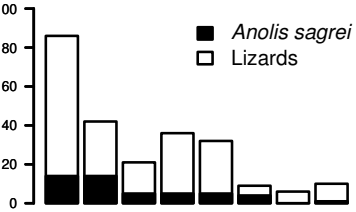

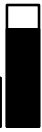

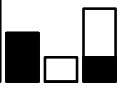

250
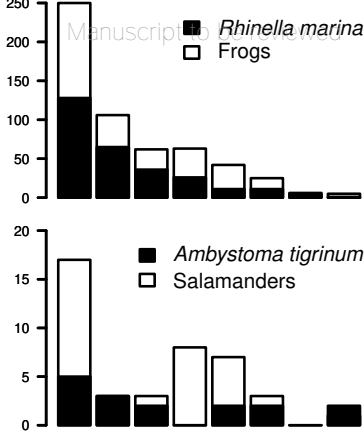

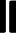

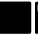

80

- Boiga irregularis

$\square$ Snakes

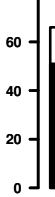

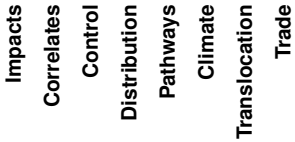

- Trachemys scripta

ㅁ Turtles

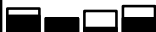

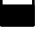

- Ambystoma tigrinum

ㅁ Salamanders
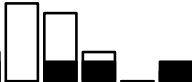

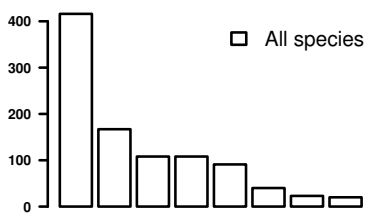

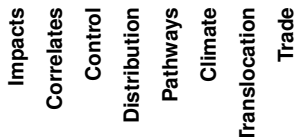

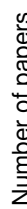

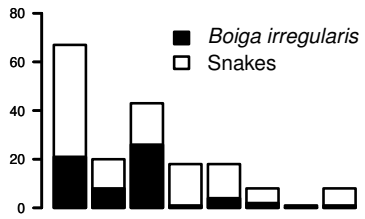




\section{Figure 5 (on next page)}

The geographic distribution of studies on non-native reptile and amphibian species.

(a) The geographic distribution of 789 studies on non-native reptile and amphibian species (20 global studies have been scored for each country and state). (b) The difference between the number of species that have been included in studies pertaining to a particular country and the number of species known to be established in that country (Kraus 2009), normalized to the largest difference. (c) The difference between the number of studies conducted in a particular country and the number of species known to be established in that country (Kraus 2009), normalized to the largest difference. 


\section{(a) Number of studies}

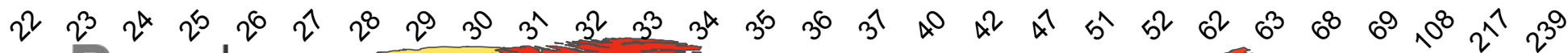

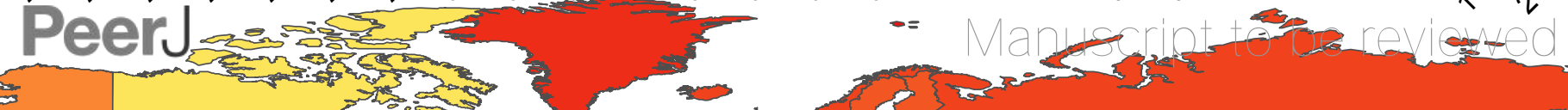

(b) Normalised differential between species studied and invasive species

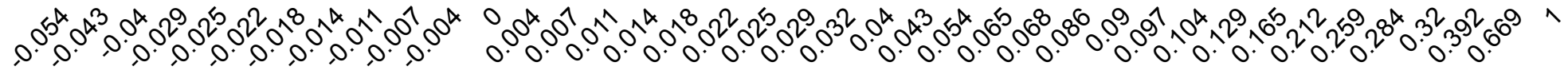

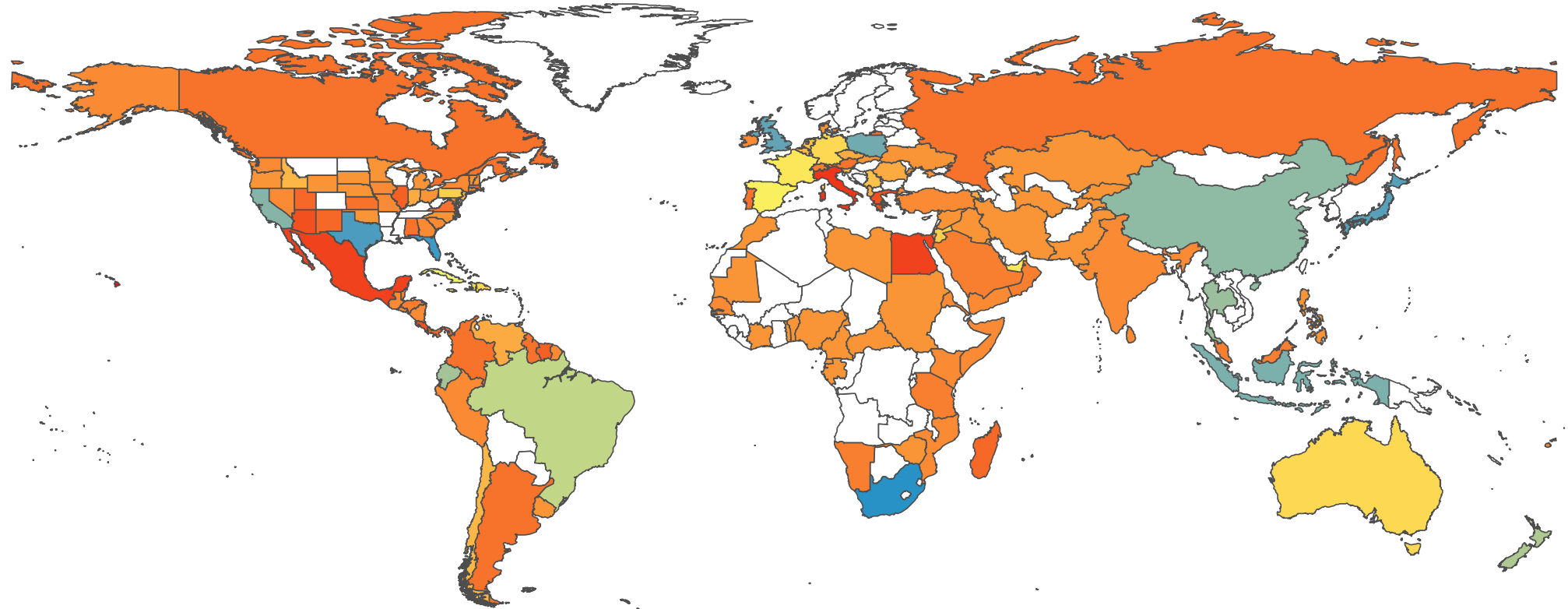

(c) Normalised differential between studies done and invasive species

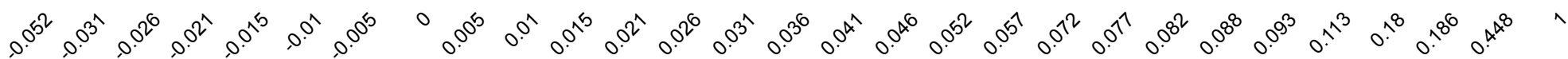

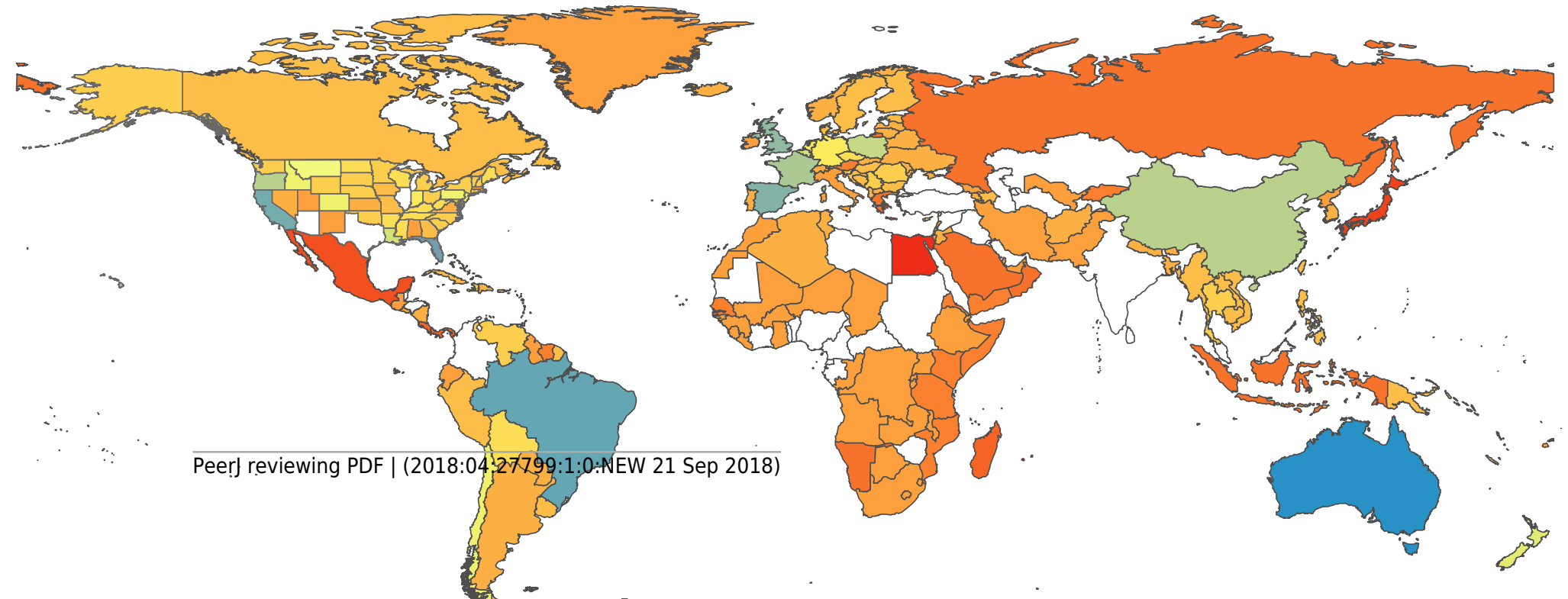




\section{Table $\mathbf{1}$ (on next page)}

Representation of herpetofaunal groups of reptiles and amphibians across papers from the systematic review 
1 Table 1. Representation of herpetofaunal groups of reptiles and amphibians across papers from

2 the systematic review

\begin{tabular}{|l|l|}
\hline Group & Number of papers (out of 836) \\
\hline Crocodiles & $22(3 \%)$ \\
\hline Frogs & $487(58 \%)$ \\
\hline Lizards & $198(24 \%)$ \\
\hline Salamanders & $33(4 \%)$ \\
\hline Snakes & $149(18 \%)$ \\
\hline Turtles & $131(16 \%)$ \\
\hline
\end{tabular}

3 


\section{Table 2 (on next page)}

Success rates for introductions and species in each herpetofaunal group of reptiles and amphibians (lizards, crocodiles, snakes, turtles, frogs and salamanders) as per Kraus (2009). 
1 Table 2. Success rates for introductions and species in each herpetofaunal group of reptiles and amphibians (lizards, crocodiles,

2 snakes, turtles, frogs and salamanders) as per Kraus (2009).

\begin{tabular}{|c|c|c|c|c|c|c|c|c|c|c|}
\hline & \multirow[b]{2}{*}{$\begin{array}{l}\text { Total } \\
\text { species } \\
\text { (Frost 2017; } \\
\text { Uetz, Freed } \\
\text { \& Hošek } \\
\text { 2017) }\end{array}$} & \multirow[b]{2}{*}{$\begin{array}{l}\text { Number of species } \\
\text { included in our } \\
\text { review (\% of total } \\
\text { species described } \\
\text { per herpetofaunal } \\
\text { group) }\end{array}$} & \multicolumn{3}{|c|}{ Introduction success } & \multicolumn{3}{|c|}{ Species success } & \multicolumn{2}{|c|}{ Proportion of taxonomic sampling } \\
\hline Order & & & $\begin{array}{l}\text { Total } \\
\text { introduct } \\
\text { ions } \\
\text { Kraus } \\
(2009)\end{array}$ & $\begin{array}{l}\text { Successful } \\
\text { introductio } \\
\text { ns Kraus } \\
(2009)\end{array}$ & $\begin{array}{l}\text { Success rate } \\
\text { of } \\
\text { introduction } \\
\text { s Kraus } \\
(2009)\end{array}$ & $\begin{array}{l}\text { Total } \\
\text { species } \\
\text { introduced } \\
\text { Kraus } \\
(2009) \\
\text { (approximat } \\
\text { e) }\end{array}$ & $\begin{array}{l}\text { Successful } \\
\text { species } \\
\text { Kraus } \\
(2009)\end{array}$ & $\begin{array}{l}\text { Success rate } \\
\text { of species } \\
\text { Kraus } \\
(2009)\end{array}$ & $\begin{array}{l}\text { Proportion of } \\
\text { species } \\
\text { introduced } \\
\text { outside of native } \\
\text { range }\end{array}$ & $\begin{array}{l}\text { Proportion of } \\
\text { species } \\
\text { naturalised/invasi } \\
\text { ve outside of } \\
\text { native range }\end{array}$ \\
\hline Lizards & 6459 & $347(5.4 \%)$ & 716 & 445 & $62 \%$ & 243 & 139 & $57 \%$ & $3.8 \%$ & $2.2 \%$ \\
\hline Crocodiles & 25 & $14(56 \%)$ & 29 & 3 & $10 \%$ & 7 & 1 & $14 \%$ & $28 \%$ & $4.0 \%$ \\
\hline Snakes & 3619 & $320(8.8 \%)$ & 370 & 115 & $31 \%$ & 139 & 30 & $22 \%$ & $3.8 \%$ & $0.8 \%$ \\
\hline Frogs & 6776 & $223(3.3 \%)$ & 508 & 313 & $62 \%$ & 147 & 82 & $56 \%$ & $2.2 \%$ & $1.2 \%$ \\
\hline Salamanders & 713 & $38(5.3 \%)$ & 81 & 35 & $43 \%$ & 37 & 19 & $51 \%$ & $5.2 \%$ & $2.7 \%$ \\
\hline Caecilians & 206 & $2(1 \%)$ & & & & & & & & \\
\hline
\end{tabular}




\section{Table 3(on next page)}

Overlap between species included in papers in the review and species documented by Kraus (2009), the most comprehensive database of introduced reptiles and amphibians currently available 
1 Table 3: Overlap between species included in papers in the review and species documented by Kraus (2009), the most comprehensive

2 database of introduced reptiles and amphibians available at the time of the review

\begin{tabular}{|l|l|l|l|}
\hline & $\begin{array}{l}\text { Number of species in } \\
\text { Kraus database }\end{array}$ & $\begin{array}{l}\text { Percentage of } \\
\text { taxa in Kraus }\end{array}$ & $\begin{array}{l}\text { Percentage of } \\
\text { species in } \\
\text { Kraus }\end{array}$ \\
\hline $\begin{array}{l}\text { Species not identified to } \\
\text { species level in Kraus }\end{array}$ & 65 & $10 \%$ & NA \\
\hline $\begin{array}{l}\text { Species not recorded in any of } \\
\text { the papers in this review }\end{array}$ & 43 & $6 \%$ & $7 \%$ \\
\hline $\begin{array}{l}\text { Species in this review that only } \\
\text { appear in global or } \\
\text { multiregional studies }\end{array}$ & 177 & $27 \%$ & $29 \%$ \\
\hline $\begin{array}{l}\text { Species studied in more } \\
\text { localities (states and countries) } \\
\text { than recorded in Kraus }\end{array}$ & 107 & $16 \%$ & $18 \%$ \\
\hline $\begin{array}{l}\text { Species studied in the same } \\
\text { number of localities as } \\
\text { recorded in Kraus }\end{array}$ & 121 & $18 \%$ & $20 \%$ \\
\hline $\begin{array}{l}\text { Species studied in fewer } \\
\text { localities than recorded in } \\
\text { Kraus }\end{array}$ & 197 & $30 \%$ & $33 \%$ \\
\hline $\begin{array}{l}\text { Total species in Kraus (2009) } \\
\text { identified to species level }\end{array}$ & $602^{1}$ plus 65 taxa not & 667 & 602 \\
\hline
\end{tabular}

3

\footnotetext{
${ }^{1}$ Another 557 taxa were listed in papers in this review but do not appear in the Kraus (2009) database
} 